\title{
Effects of cigarette smoke condensate on the production and characterization of exopolysaccharides by Bifidobacterium
}

\author{
JINQIANG HU ${ }^{1}$, TAO WEI ${ }^{1}$, SIWEN SUN ${ }^{1}$, \\ AIJING ZHAO ${ }^{2}$ and CHUNPING XU ${ }^{1}$ \\ ${ }^{1}$ College of Food and Biological Engineering, Zhengzhou \\ University of Light Industry (Kexue campus), Kexue Road 166, \\ Zhengzhou High-tech Zone, Zhengzhou, Henan, 453000, P.R. China \\ ${ }^{2}$ College of Life Science, Henan Normal University, \\ Jianshedong Road 46, Xinxiang, Henan, 453007, P.R.China
}

Manuscript received on October 9, 2014; accepted for publication on December 19, 2014

\begin{abstract}
The aim of the study was to investigate the effect of cigarette smoke on the production and characterization of exopolysaccharides (EPSs) produced by Bifidobacterium. Cigarettes of Shanhua brand (nicotine: 1.1 $\mathrm{mg}$, tar: $11 \mathrm{mg}$ ) were utilized to prepare a cigarette smoke condensate (CSC). The standard strain of Bifidobacterium animalis was cultured in MRS media under anaerobic addition of CSC. The results showed that CSC significantly decreased the growth of B. animalis as well as EPSs and acetic acid production. Furthermore, two EPSs fractions (Fr-I and Fr-II) were isolated and purified for chemical and molecular determination. By comparison with control, CSC was found to be of great impact on EPSs carbohydrate composition. The molecular weight mass of Fr-I changed from $3.33 \times 10^{5} \mathrm{~g} / \mathrm{mol}$ (without CSC) to $2.99 \times 10^{5}$ (with CSC). In conclusion, in vitro studies revealed that CSC was directly able to affect the production of metabolites for $B$. animalis, which could be an essential factor in certain pathological disorders.
\end{abstract}

Key words: Exopolysaccharides, cigarette smoke condensate, Bifidobacterium, acetic acid.

\section{INTRODUCTION}

The human body is colonized by a vast number of microbes, collectively referred to as human microbiota (Turroni et al. 2008). Many bacterial species have evolved and adapted to live and grow in the human intestine. The intestinal habitat of an individual contains 300-500 different species of bacteria (Rana and Bhardwaj 2008). The link

Correspondence to: Chunping Xu E-mail: xuchunping05@163.com / c.p.xu@zzuli.edu.cn between these microbes and human health is the focus of a growing number of research initiatives. Recent studies suggest that microflora have specific metabolism to cause certain pathological disorders including multisystem organ failure, colon cancer, and inflammatory bowel diseases (Guarner 2006).

Cigarette smoking is an important etiologic factor linked to the development of many diseases such as pulmonary, cardio and cerebrovascular diseases, cancers, asthma, chronic obstructive pulmonary disease (COPD) and several others 
(Karimi et al. 2006). Cigarette smoke is a complex mixture of over 4700 identified constituents that include numerous reactive substances such as a large quantity of reactive aldehydes, free radical species and diverse metals (Hecht 2006). Cigarette smoke condensate (CSC) has been reported to elicit morphological and transcriptional changes that suggest epithelialto-mesenchymal transition (EMT) in cultured bronchial epithelial cells (Polk 2012). Zonuz et al. (2008) reported that the growth of Streptococcus mutans and Streptococcus sanguis is accelerated in the vicinity of CSC. CSC has also been reported to interfere with the adhesion and biofilm formation in contact with Streptococcus mutans and Candida albicans cells (Baboni et al. 2010). However, there have been few studies to date reporting results about the destruction of bacterial flora by swallowed CSC together with saliva and during smoking and biological activity correlating between CSC and intestinal bacterial flora.

As is well known, bifidobacteria can be found as a part of the normal gut flora of healthy humans and are often the predominant species. They have long been recognized as bacteria with probiotic, nutritive, and therapeutic properties and have a wide range of therapeutic value in humans. There are some reports on the bioactivities of EPSs produced by Bifidobacterium, suggesting that EPSs might contribute to human health as prebiotics or due to antioxidant, antitumor, antiulcer, immunomodulating, or cholesterollowering activities (Korakli et al. 2002, Xu et al. 2011). In this study, the influence of CSC on the production and molecular characterization of EPSs produced form Bifidobacterium animalis was studied aiming towards achieving a better simulation and understanding of the mechanisms of how swallowed smoke together with saliva during smoking may influence the growth of bacteria in intestinal bacterial flora.

\section{MATERIALS AND METHODS}

Cigarette SMoke Condensate

The volatile products in CSC were collected by washing the smoke from the complete burn of 5 cigarettes (brand: Shanhua) containing $11 \mathrm{mg}$ of tar, $1.1 \mathrm{mg}$ of nicotine, and $15 \mathrm{mg}$ of carbon monoxide per cigarette (Zhengzhou tobacco cigarette Co. Ltd, China) in an in-house smoking machine containing $100 \mathrm{~mL}$ of distilled water. The water containing CSC was filtered through a pore membrane $(0.44 \mathrm{~mm}$, Millipore) immediately after the cigarettes were burned (Baboni et al. 2010). A final concentration of $0.45 \mathrm{mg} \mathrm{TPM} / \mathrm{mL}$ was determined in the filtrate. This primary stock was stored at $-70^{\circ} \mathrm{C}$. Dilutions were made in complete cell culture medium as 1:20, 2:20 and 3:20 (v/v) using the thawed aliquots.

MICROORGANISMS

The microorganism strain of Bifidobacterium animalis CGMCC 1.1852 was purchased from the China General Microbiological Culture Collection Center (Beijing, China). The microorganisms were maintained on PTYG agar slants (peptone $0.25 \mathrm{~g}$; tryptone $0.25 \mathrm{~g}$; yeast extract $0.6 \mathrm{~g}$; glucose 0.5 g; $\mathrm{MgSO}_{4} .7 \mathrm{H}_{2} \mathrm{O} 0.03 \mathrm{~g} ; \mathrm{CaCl}_{2} .2 \mathrm{H}_{2} \mathrm{O} 0.003 \mathrm{~g}$; bromothymol blue $0.025 \mathrm{~g}$ and agar $15 \mathrm{~g}$, dissolved in 1 litre of distilled water), stored at $4^{\circ} \mathrm{C}$ and subcultured periodically (Korakli et al. 2002). The seed culture was grown in a $250 \mathrm{~mL}$ flask containing $50 \mathrm{~mL}$ MRS medium at $37^{\circ} \mathrm{C}$ for $18 \mathrm{~h}$ anaerobically $\left(80 \% \mathrm{~N}_{2}, 10 \% \mathrm{CO}_{2}, 10 \% \mathrm{H}_{2}\right)$ using the Gas Pak culture system (BBL, Cockeysville, MD) (Feng et al. 2005). Cell culture experiments were performed in a $500 \mathrm{~mL}$ Erlenmeyer flask containing $200 \mathrm{~mL}$ of cell medium (MRS medium added the CSC filtrates as mentioned above) after inoculating with $10 \%(\mathrm{v} / \mathrm{v})$ of seed culture.

\section{Cell Growth, Acetic AcID AND EPSs Production}

Bacterial growth was estimated by colony counting on the PTYG agar medium. Plates were incubated 
anaerobically for $48 \mathrm{~h}$ at $37^{\circ} \mathrm{C}$. After flask culture, cells were removed from the culture medium by centrifugation at $8,000 \mathrm{~g}$ for $10 \mathrm{~min}$ at $4^{\circ} \mathrm{C}$. The concentrated supernatant was precipitated with three times volume of $95 \%(\mathrm{v} / \mathrm{v})$ cold ethanol overnight at $4^{\circ} \mathrm{C}$. The crude EPSs were collected by centrifugation at $8,000 \mathrm{~g}$ for $10 \mathrm{~min}$ discarding the supernatant. The precipitate of EPS was redissolved in distilled water and its concentration determined by the phenolsulfuric acid method (Hwang et al. 2003). Acetic acid content was determined using a modified hydroxyl biphenyl assay according to the procedure of the Carbazole-sulfuric acid method (Vuyst et al. 2001).

PURIFICATION AND CHARACTERIZATION OF TWO EPSS

FRACTIONS

EPSs were dissolved in $0.2 \mathrm{M} \mathrm{NaCl}$ buffer and loaded onto a Sepharose CL-6B column (2.4 $\mathrm{cm} \times 100 \mathrm{~cm}$, Sigma Chemical Co., St Louis, MO). The column was eluted with the same buffer at a flow rate of $0.6 \mathrm{~mL} / \mathrm{min}$. Protein concentration was determined according to the Bradford method using bovine serum albumin as standard (Bradford 1976). The total sugar content in the EPSs was determined by phenol sulfuric acid method using glucose as the standard (Dubois et al. 1956). The protein moiety in the EPSs was monitored by measuring the absorbance at $280 \mathrm{~nm}$, whilst the carbohydrate moiety was monitored at $490 \mathrm{~nm}$.

To determine the monosaccharide composition of EPSs, the corresponding EPSs fraction $(5 \mathrm{mg})$ was hydrolyzed with $2 \mathrm{~mL}$ of $2 \mathrm{M}$ trifluoroacetic acid (TFA) at $110^{\circ} \mathrm{C}$ for $2 \mathrm{~h}$, aiming to identify and quantify monosaccharide profile and content. The hydrolysate was repeatedly co-concentrated with methanol, reduced with $\mathrm{NaBH}_{4}$ for 30 min at $20^{\circ} \mathrm{C}$ and acetylated with acetic anhydride and pyridine at $100^{\circ} \mathrm{C}$ for $20 \mathrm{~min}$. The internal standard sugars were prepared and subjected to GC-MS analysis, separately in the same way. The alditol acetates of EPSs fraction were analyzed by GC-MS (Varian Co., Model: Star 3600 CX, Lexington, MA, USA) fitted with a fused silica capillary column (Na form, 300 $\mathrm{mm} \times 0.25 \mathrm{~mm}$, Supelco Inc., Bellefonte, PA, USA) and a flame ionization detector (Ma et al. 2013).

To detect the main functional groups of EPSs, FT-IR Spectroscopy measurements were recorded in a Bruker Tensor 27 Mattson Instrument. The purified EPSs fractions (1 mg) were ground with $300 \mathrm{mg} \mathrm{KBr}$ powder, subsequently pressed into pellets, and measurements were conducted within the 550 to $4,000 \mathrm{~cm}^{-1}$ range. Spectra were corrected for wave number dependent signal-detection efficiency of the setup using the white light spectrum of a temperature-calibrated tungsten band lamp (Zheng et al. 2014).

The molecular weights of EPSs were estimated by SEC coupled with MALLS Dawn DSP detector (Wyatt Technology, Santa Babara, CA) and a Refractive Index (RI) detector (Optilab rEX, Wyatt Technology, Santa Barbara, CA). EPSs samples were dissolved in a $0.1 \mathrm{M}$ PBS buffer $(\mathrm{pH}=6.8)$ containing $0.04 \%$ diaminotetraacetic acid-disodium salt $\left(\mathrm{Na}_{2} \mathrm{EDTA}\right)$ and $0.01 \%$ sodium azide and filtered through $0.25 \mu \mathrm{m}$ filter membranes (Millex HV type, Millipore Co., Bedford, MA) prior to injection into the SEC/MALLS system. The chromatographic system consisted of a degasser (Degasys, DG-1200, uniflow, HPLC Technology, Macclesfield, UK), a SSI 222D pump (Scientific Systems, State College, PA, USA) a single-piston isocratic, a pulse-dampened HPLC pump (Model 590 Programmable Solvent Delivery Module, Waters Co., Milford, MA), an injection valve (Rheodyne, Inc., Cotati, CA) fitted with a $500 \mu \mathrm{L}$ loop, and two SEC columns (Shodex OH Pack SB803 and 805 HQ, JM Science Inc., Buffalo, NY) connected in series. The flow rate was $0.75 \mathrm{~mL} /$ min and the injection volume and concentration was $100 \mathrm{~mL}$ and $2 \mathrm{mg} / \mathrm{mL}$, respectively. During the calculation of molecular weights of each EPSs, the value of $\mathrm{dn} / \mathrm{dc}$ (specific refractive index increment) was selected from literature data (Jumel et al. 1996), in which the estimated $\mathrm{dn} / \mathrm{dc}$ was $0.14 \mathrm{~mL} / \mathrm{g}$. 
Calculations of molecular weight and root mean square (RMS) radius of gyration for each EPSs were performed using Astra 4.72 software (Wyatt Technology). The RMS radii of each polysaccharide were determined from the slope by extrapolation of the first-order Debye plot (Wyatt 1993).

\section{STATISTICAL ANALYSES}

Data were expressed as means \pm S.D. The results were analyzed for statistical significance by oneway analysis of variance (ANOVA) test using the Statistical Package of the Social Science (SPSS) version 11.0 (SPSS Inc., Chicago, IL, USA). Group means were considered to be significantly different at $\mathrm{P}<0.05$, as determined by the technique of protective least-significant difference (LSD).

\section{RESULTS AND DISCUSSION}

\section{EFFECT OF CSC ON CELL GROWTH, EPSS AND ACETIC ACID}

\section{PRODUCTION}

To evaluate the level of interference of CSC on the growth of $B$. animalis, a comparison between the experimental groups (with different amount of addition of CSC) and controls (without CSC) were performed. Results shown in Fig. 1 indicated that cell number, EPSs and acetic acid yields presented a decline tendency at increasing concentrations of CSC after 48h, though not all differences were statistically significant. These results proved that cigarette smoke inhibited the in vitro growth of B. animalis and decreased secretion of EPSs and acetic acid. EPSs produced by $B$. animalis have been reported to potentially exert beneficial effects as prebiotic substrates on human health or due to antitumoral, antiulcer, immune-modulating and/or cholesterol-reducing activities (Korakli et al. 2002). Acetic acid can increase the acidity of the intestine and curb the reproduction of many harmful bacteria (Vuyst et al. 2001). The decrease of EPSs and acetic acid production clearly indicates that CSC may not have any beneficial effects on bacterial intestinal flora. Zhu et al. (2008) also reported that elicitor, an important component of pathogen-derived compounds (e.g., oligosaccharides, glycopeptides and lipids, etc), was regarded as being an effective ingredient in altering polysaccharide biosynthesis during fungal submerged fermentation.

EFFECT OF CSC ON THE StRUCTURAL PROPERTIES OF EPSS

EPSs from submerged culture of $B$. animalis with and without CSC were obtained upon precipitation with ethanol. Two fractions (designated as Fr-I and
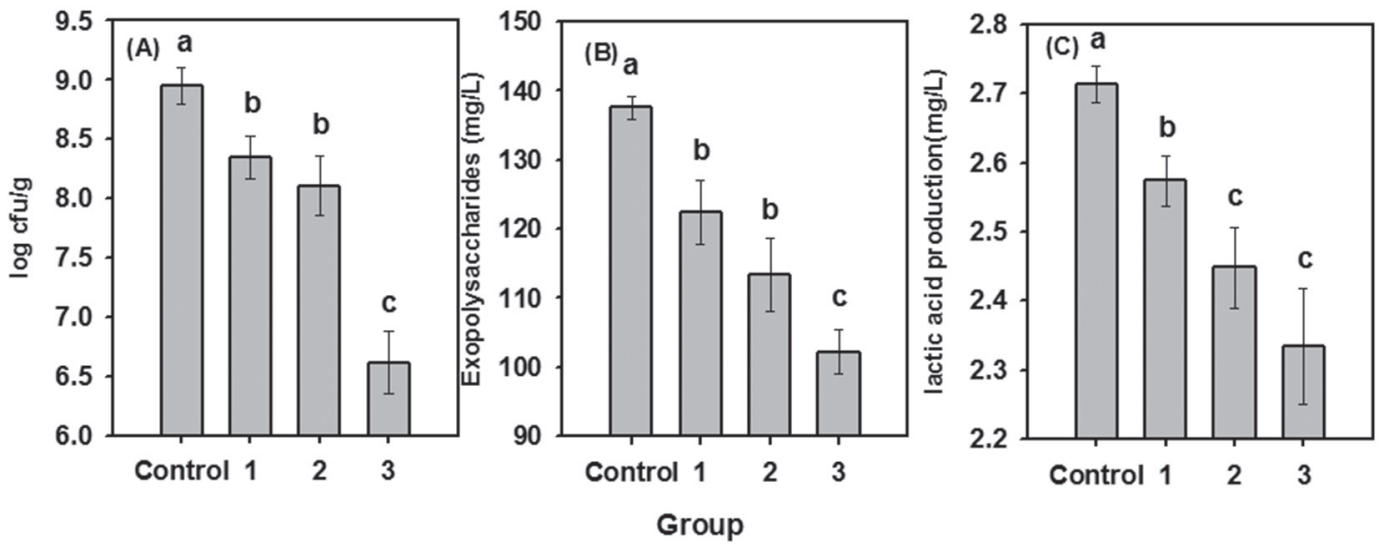

Figure 1 - Effect of CSC on cell concentration (A), expolysaccharides (B) and acetic acid (C) production by B. animalis obtained in PTYG agar medium. Control means medium without CSC. Group 1, 2 and 3 mean the radios of CSC and medium are 1:20, 2:20 and 3:20 (v/v), respectively. a, b, c Statistical analysis at 95\% confidence level with same letters in the same figure indicating no significant difference. 
Fr-II) of EPSs were co-eluted after gel filtration chromatography on Sepharose CL-6B as shown in Figure 2. This is in agreement with the results reported by Xu et al. (2011). They purified the EPSs from $B$. animalis by anion-exchange chromatography and revealed the presence of two fractions. Both, Figure $2 \mathrm{~A}$ and $2 \mathrm{~B}$, show the presence of protein peaks for Fr-II. However, electrophoresis analysis would need to be conducted in order to ascertain whether the proteins are bound to the polysaccharide (forming protein-polysaccharide complexes) or just have similar molecular weight as compared to Fr-II (same elution time) according to the different charge between polysaccharides and proteins.

The detailed monosaccharide compositions from the carbohydrate fraction in the two EPSs fractions could be worked out from trifluoroacetic acid hydrolysis and GC-MS analysis as illustrated in Table I. The results pointed to fructose, mannose and glucose as the major monosaccharide in all fractions. However, the ratios of the three main monosaccharides for Fr-I and Fr-II were remarkably different between culture growths in the presence and absence of CSC. These results indicated that CSC could alter the secondary metabolites biosynthesis pathway. Xu et al. (2006) also found that fermentation conditions have a strong influence on the molecular weight and carbohydrate compositions of EPSs produced by submerged culture of Paecilomyces tenuipes. Results also revealed that the total carbohydrate content of the two groups of EPSs was found to be $86.5 \sim 96.5 \%$, suggesting that both fractions were mainly comprising polysaccharides.

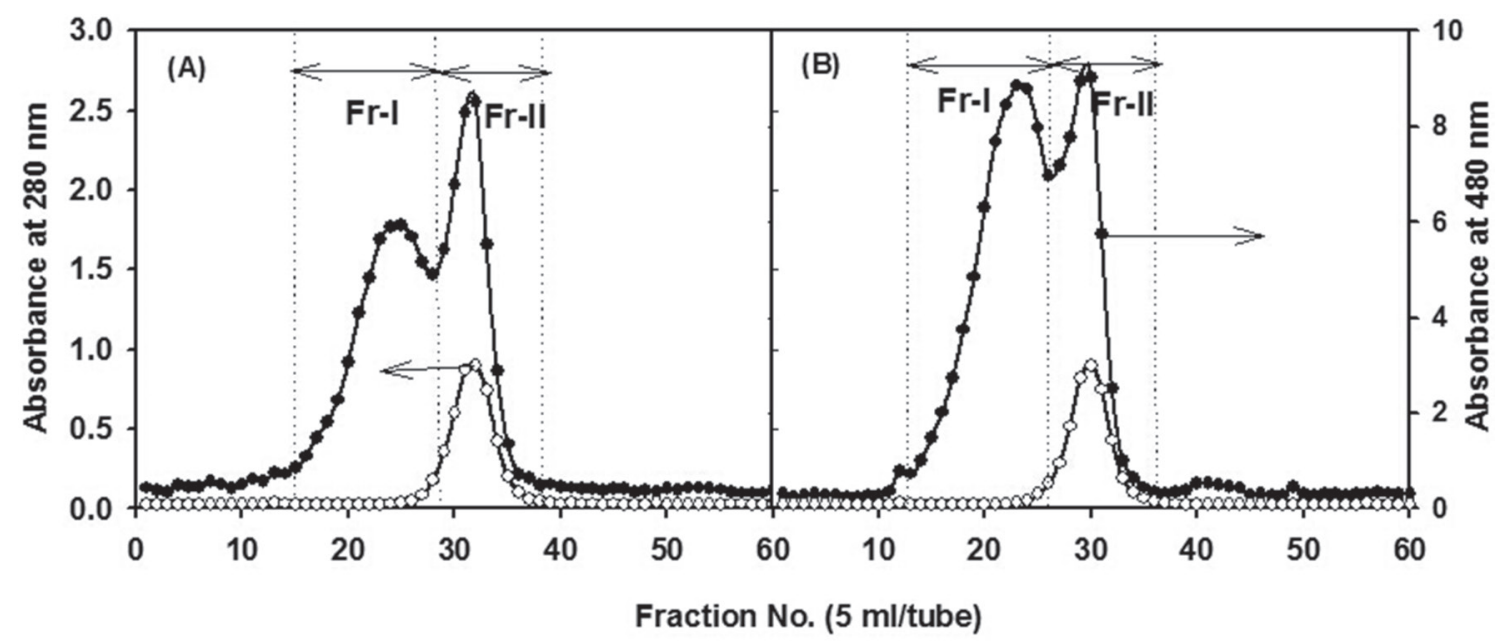

Figure 2 - Elution profiles of the EPSs from submerged culture of $B$. animalis with and without cigarette smoke condensate (CSC) in Sepharose CL-6B chromatography. Eluate was analyzed by measuring the absorbance at $490 \mathrm{~nm}$ for carbohydrate $(\bullet)$ and the absorbance at $280 \mathrm{~nm}$ for protein $(\circ)$. (A) without CSC, (B) with CSC.

FT-IR is an effective analytical instrument to characterize functional groups. Typical IR spectra for both EPS fractions are compiled in Figure 3. All samples exhibited a broad stretching intense characteristic band at ca. $3280 \mathrm{~cm}^{-1}$ typical of $-\mathrm{OH}$ groups as well as a weak C-H band at ca. $2930 \mathrm{~cm}^{-1}$. The characteristic band at ca. $1635-1642 \mathrm{~cm}^{-1}$ could be correlated to the stretching vibration of the carbonyl group $(\mathrm{C}=\mathrm{O})$ in polysaccharides (Zhao et al. 2010). A small peak around $1536-1559 \mathrm{~cm}^{-1}$ corresponding to amino groups was also observed in the FTIR spectra. Bands at ca. $1028 \mathrm{~cm}^{-1}$ in Fr-I suggested the presence of C-O types of linkages (Leung et al. 2009). Similar profiles in Fr-I with and without CSC indicated that CSC would not significantly change the functional groups of Fr-I, in a way similar to those for Fr-II. 
TABLE I

Carbohydrate composition in the purified group of EPS fractions (Fr-I and Fr-II) produced from submerged culture of $B$. animalis with and without cigarette smoke condensate (CSC).

\begin{tabular}{ccccc}
\hline \multirow{2}{*}{$\begin{array}{c}\text { Carbohydrate } \\
\text { composition (\%) }\end{array}$} & \multicolumn{2}{c}{ Culture without CSC } & \multicolumn{2}{c}{ Culture with CSC } \\
\cline { 2 - 5 } & Fr- I & Fr- II & Fr- I & Fr- II \\
\hline Mannose & $43.64 \pm 2.03$ & $27.28 \pm 1.87$ & $34.08 \pm 2.37$ & $53.38 \pm 1.69$ \\
Arabinose & $0.16 \pm 0.01$ & $5.51 \pm 0.69$ & $0.69 \pm 0.06$ & $2.24 \pm 0.38$ \\
Rhamnose & $1.35 \pm 0.08$ & $1.81 \pm 0.28$ & $0.94 \pm 0.09$ & $2.27 \pm 0.16$ \\
Galactose & $2.87 \pm 0.17$ & $2.58 \pm 0.12$ & $2.14 \pm 0.15$ & $3.00 \pm 0.11$ \\
Xylose & $0.53 \pm 0.03$ & $1.55 \pm 0.27$ & $0.35 \pm 0.02$ & $2.03 \pm 0.25$ \\
Glucose & $8.39 \pm 0.99$ & $42.64 \pm 3.24$ & $11.59 \pm 1.13$ & $15.85 \pm 1.45$ \\
Fructose & $42.85 \pm 3.71$ & $16.54 \pm 1.89$ & $50.06 \pm 3.21$ & $20.85 \pm 1.61$ \\
Ribose & $0.21 \pm 0.08$ & $2.09 \pm 0.17$ & $0.15 \pm 0.03$ & $0.38 \pm 0.04$ \\
Total carbohydrate & $95.33 \pm 3.71$ & $86.48 \pm 2.56$ & $95.50 \pm 3.11$ & $86.98 \pm 3.45$ \\
content $^{\mathrm{a}}$ & & & & \\
\hline
\end{tabular}

${ }^{a}$ Total carbohydrate content indicates the percentage of total amount of carbohydrate to sum of total amount of carbohydrates and proteins.

\section{EFFeCt OF CSC ON MOLECUlar Properties of EPS}

The molecular properties of EPS were determined using MALLS and RI detection and are summarized in Table II. The average molar mass weight $(M w)$ of Fr-I generated in the absence of CSC $\left(3.33 \times 10^{5} \mathrm{~g} / \mathrm{mol}\right)$ was larger in comparison to that observed for CSC-added Fr-I (CSC 2.99 $\times 10^{5}$ ). However, no significant $M w$ differences were observed for Fr-II in the presence or absence of CSC. Polydispersity value $(M \mathrm{w} / M \mathrm{n})$ is important due to the relevance and significant influence of molecular weight distribution on the functional properties of polysaccharides. Results for Fr-I indicated generally higher values of polydispersity ratio as compared to Fr-II, indicating that molecules of Fr-I are remarkably more dispersed in aqueous solutions when forming large aggregates with respect to Fr-II (Hwang et al. 2003). The RMS radii for four peaks ranged from 14.1 to $30.8 \mathrm{~nm}$ with no clear trends.

TABLE II

Relevant molecular parameters of EPS fractions (Fr-I and Fr-II) and the double logarithmic plots of root mean square radius vs molecular mass for four fractions of EPS produced by submerged B. animalis with and without cigarette smoke condensate (CSC) in MALLS analysis. ${ }^{a}$

\begin{tabular}{ccccc}
\hline \multirow{2}{*}{ Parameters } & \multicolumn{2}{c}{ Culture without CSC } & \multicolumn{2}{c}{ Culture with CSC } \\
\cline { 2 - 5 } & Fr-I (error \%) & Fr-II (error \%) & Fr-I (error \%) & Fr-II (error \%) \\
\hline $\mathrm{M}_{\mathrm{n}}\left(\mathrm{g} \mathrm{mol}^{-1}\right)$ & $1.025 \times 10^{5}(4)$ & $5.876 \times 10^{3}(2)$ & $8.082 \times 10^{4}(2)$ & $7.172 \times 10^{3}(2)$ \\
$\mathrm{M}_{\mathrm{w}}\left(\mathrm{g} \mathrm{mol}^{-1}\right)$ & $3.332 \times 10^{5}(0.9)$ & $1.128 \times 10^{4}(0.7)$ & $2.990 \times 10^{5}(0.4)$ & $1.185 \times 10^{4}(3)$ \\
$\mathrm{M}_{\mathrm{z}}\left(\mathrm{g} \mathrm{mol}^{-1}\right)$ & $1.640 \times 10^{6}(1)$ & $3.152 \times 10^{4}(2.9)$ & $2.544 \times 10^{6}(0.6)$ & $2.071 \times 10^{4}(1.2)$ \\
$\mathrm{M}_{\mathrm{w}} / \mathrm{M}_{\mathrm{n}}$ & $3.251(4)$ & $1.920(0.7)$ & $3.700(2)$ & $1.652(4)$ \\
$\mathrm{R}_{\mathrm{n}}(\mathrm{nm})$ & $30.8(3.3)$ & $20.4(1.5)$ & $14.1(3.3)$ & $19.8(1.5)$ \\
$\mathrm{R}_{\mathrm{w}}(\mathrm{nm})$ & $27.5(1.5)$ & $27.4(1.6)$ & $14.2(2.1)$ & $21.8(1.6)$ \\
$\mathrm{R}_{\mathrm{z}}(\mathrm{nm})$ & $23.1(0.7)$ & $53.3(1.1)$ & $20.2(3)$ & $28.4(1.6)$ \\
double logarithmic plots & & & & $\mathrm{n} / \mathrm{a}$ \\
$\begin{array}{c}\text { of root mean square } \\
\text { radius vs molecular mass }\end{array}$ & $0.11(0.01)$ & $\mathrm{n} / \mathrm{a}$ & $0.18(0.01)$ & \\
\hline
\end{tabular}

${ }^{a} M_{n}, M_{w}$, and $M_{z}$ refer number-, weight-, $z$-average molecular weight, respectively. $M_{w} / M_{n}$ means polydispersity ratio. $\mathrm{R}_{\mathrm{n}}, \mathrm{R}_{\mathrm{w}}$, and $\mathrm{R}_{\mathrm{z}}$ refer number-, weight-, $\mathrm{z}$-average square mean radius of gyration, respectively. 

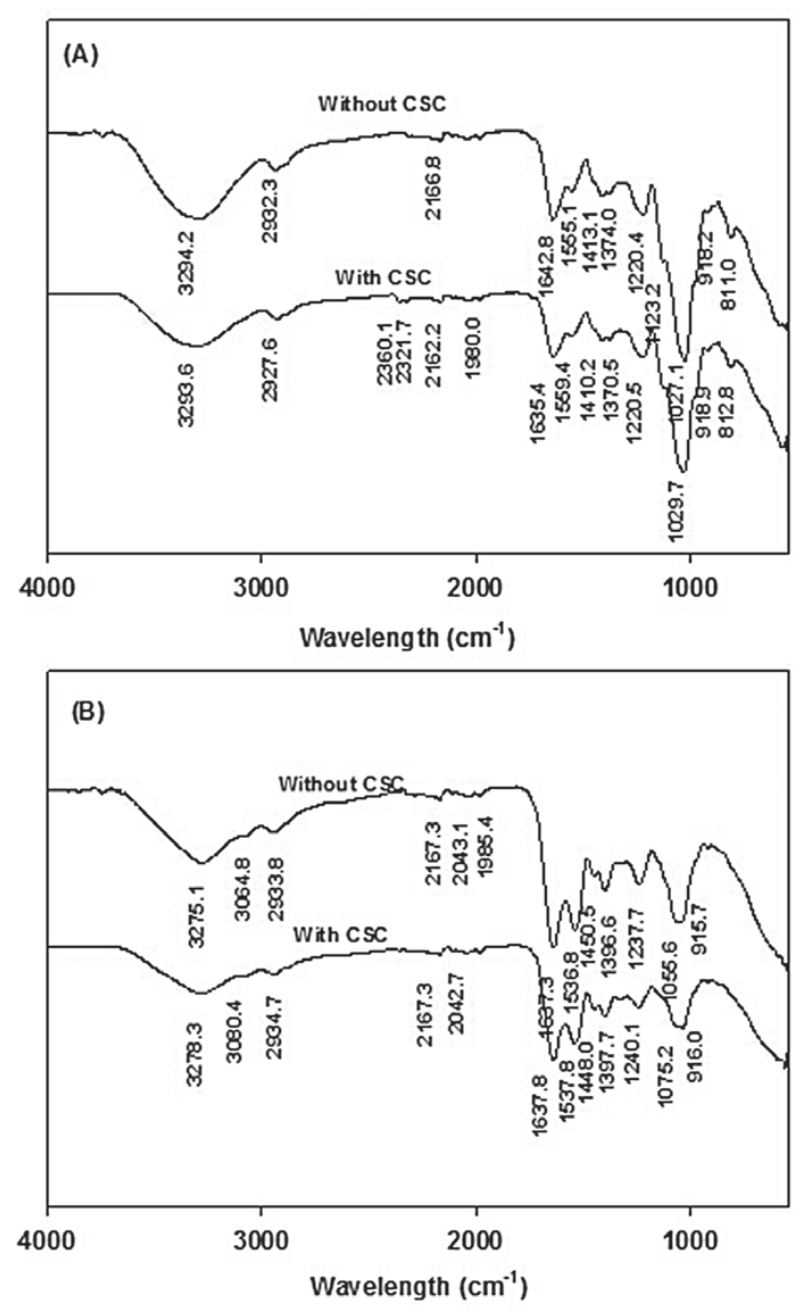

Figure 3 - The FT-IR spectra of the EPSs fractions (Fr-I and Fr-II) produced by submerged culture of $B$. animalis with and without cigarette smoke condensate (CSC). (A) Fr-I, (B) Fr-II.

The slopes for Fr-I and Fr-II in the double logarithmic plots of RMS radius versus molecular mass are depicted in Table II. The gross conformation of EPS in aqueous solution (e.g. random coil, compact sphere, stiff rod, or combinations of them) could be identified from the double logarithmic plot of RMS radius vs. molecular mass of EPS according to the following equations:

$$
\log r_{i}=k+a \log M_{i}
$$

Where $r_{i}$ is the RMS radius of an EPS molecule, $M_{i}$ is the molar mass of EPS, $k$ is the intercept at the $Y$-axis (RMS radius), and $a$ is the critical slope values to determine the molecular conformation of each EPS. For polymers of sphere-like structure, random coils, or rigid rods, their corresponding values of slope are known as $1 / 3,1 / 2$ and 1 , respectively, according to the following dimensional relationships: for globular shape, $r_{i}^{3} \infty M_{i}$; for flexible coil, $r_{i}^{2} \infty M_{i}$; rodlike chain, $r_{i} \infty M_{i}$ (Wyatt 1993). The slopes for Fr-I and Fr-II in the double logarithmic plots of RMS radius versus molecular mass are depicted in Table II. Slope values indicated 0.11 (without CSC) and 0.18 (with CSC) for F-I, respectively. These findings imply that Fr-I molecules possess spherical shapes in aqueous solution. Comparatively, the slopes for Fr-II in the double logarithmic plots of RMS radius versus molecular mass could not be detected because their molecular weights were inferior to $5 \times 10^{4} \mathrm{~g} / \mathrm{mol}$ in the aqueous system. In summary, all results from molecular properties indicated that CSC influenced the molecular size of the polysaccharide fractions rather than the structural conformation of the EPS fraction.

\section{CONCLUSION}

$B$. animalis growth and production of exopolysaccharides (EPS) and acetic acid have been found to be influenced by the presence of CSC, essentially leading to growth inhibition and decrease in metabolites content. Furthermore, CSC could also affect carbohydrate composition of EPS and molecular weight mass weight, a phenomena particularly observed for Fr-I. These findings may be an essential factor in certain intestinal dysbacteriosis and will pave the way for future investigations along the negative influence of tobacco and smoke-related condensates in microorganisms. In order to understand how the molecules in CSC affect the intestinal flora, further work on the relationship between the main toxic compositions in CSC and intestinal flora is in progress in our laboratory. 


\section{ACKNOWLEDGMENTS}

The authors acknowledge the financial support from the International Science \& Technology Cooperation Program of Henan Province (144300510061).

\section{RESUMO}

O objetivo do estudo foi investigar o efeito da fumaça de cigarro sobre a produção e caracterização de exopolissacarídeos (EPSs) produzidos por Bifidobacterium. Os cigarros de marca Shanhua (nicotina: $1,1 \mathrm{mg}$, alcatrão: $11 \mathrm{mg}$ ) foram utilizados para preparar um condensado de fumaça de cigarro (CSC). A cepa padrão de Bifidobacterium animalis foi cultivada em meio MRS sob condições anaeróbicas do CSC. Os resultados mostraram que a CSC diminuiu significativamente o crescimento de $B$. animalis, bem como EPSs e produção de ácido acético. Além disso, duas frações de EPSs (Fr-I e Fr-II) foram isoladas e purificadas para determinação de componentes químicos e moleculares. Pela comparação com o controle, observou-se que o CSC apresentou uma grande diferença na composição de hidratos de carbono EPSs. A massa do peso molecular de Fr-I passou de $3,33 \times 10^{5} \mathrm{~g} / \mathrm{mol}(\mathrm{sem} \mathrm{CSC})$ para $2,99 \times 10^{5}(\mathrm{com}$ CSC). Em conclusão, os estudos in vitro revelaram que a CSC foi capaz de afetar diretamente a produção de metabolitos de $B$. animalis, o que pode ser um fator essencial de certas desordens patológicas.

Palavras-chave: exopolissacarídeos, condensado de fumaça de cigarro, Bifidobacterium, ácido acético.

\section{REFERENCES}

BABOni FB, GuARIZA FO, MoReno AN AND Rosa EA. 2010 Influence of cigarette smoke condensate on cariogenic and candidal biofilm formation on orthodontic materials. Am J Orthod Dentofac 138(4): 427-434.

BRADFORD MM. 1976. A rapid and sensitive method for the quantitation of microgram quantities of protein utilizing the principle of protein-dye binding. Anal Biochem 72: 248-254.

Dubois M, GiLles KA, HAMilton JK, Rebers PA AND SMITH F. 1956. Colorimetric method for determination of sugars and related substances. Anal Biochem 28: 350-356.
FENG XM, ERIKSSON AR AND SCHNÜRER J. 2005. Growth of lactic acid bacteria and Rhizopus oligosporus during barley tempeh fermentation. Int J Food Microbiol 104(3): 249-256.

GUARNER F. 2006. Enteric Flora in Health and Disease. Digestion 73(1): 5-12.

HECHT SS. 2006. Cigarette smoking: cancer risks, carcinogens, and mechanisms. Langenbeck Arch Surg 391(6): 603-613.

Hwang HJ, Kim SW, XU CP, ChOI JW AND Yun JW. 2003. Production and molecular characteristics of four groups of exopolysaccharides from submerged culture of Phellinus gilvus. J Appl Microbiol 94: 708-719.

JUMELK, FIEBRIG IAND HARDING SE. 1996. Rapid size distribution and purity analysis of gastric mucus glycoproteins by size exclusion chromatography/multi angle laser light scattering. Int J Biol Macromol 18: 133-139.

Karimi K, Sarir H, Mortaz E, Smit JJ, Hosseini H, De Kimpe SJ, NiJKamp FP AND Folkerts G. 2006. Tolllike receptor-4 mediates cigarette smoke-induced cytokine production by human macrophages. Resp Res 7(1): 66-11.

KORAKLIM, GÄNZLE MGAND VOGEL RF. 2002. Metabolism by bifidobacteria and lactic acid bacteria of polysaccharides from wheat and rye, and exopolysaccharides produced by Lactobacillus sanfranciscensis. J Appl Microbiol 92: 958965.

LeUNG PH, ZhaO SN, Ho KP AND WU JY. 2009. Chemical properties and antioxidant activity of exopolysaccharides from mycelial culture of Cordyceps sinensis fungus CsHK1. Food Chem 114: 1251-1256.

Ma Y, Mao D, Geng L, Wang Z And Xu C. 2013. Production, fractionation, characterization of extracellular polysaccharide from a newly isolated Trametes gibbosa and its hypoglycemic activity. Carbohyd Polym 96: 460-465.

POLK WW. 2012. FH535 potentiation of cigarette smoke condensate cytotoxicity is associated with changes in $\beta$-catenin and EGR-1 signaling. Int J Toxicol 31(4): 380389.

RANA SV AND BHARDWAJ SB. 2008. Small intestinal bacterial overgrowth. Scand J Gastroentero 43(9): 1030-1037.

TURroni F, RIBBERA A, Foroni E, VAN Sinderen D AND VENTURA M. 2008. Human gut microbiota and bifidobacteria: from composition to functionality. Anton Leeuw Int J G 94: 35-50.

VuYst DL, VIN DF, VANINGELGEM F AND DEgeEST B. 2001 Recent developments in the biosynthesis and applications of heteropolysaccharides from lactic acid bacteria. Int Dairy J 11: 687-707.

WYATT PJ. 1993. Light scattering and the absolute characterization of macromolecules. Anal Chim Acta 272: 1-40.

Xu CP, Kim SW, Hwang HJ AND Yun JW. 2006. Production of exopolysaccharides by submerged culture of an enthomopathogenic fungus, Paecilomyces tenuipes C240 in stirred-tank and airlift reactors. Bioresource Technol 97: 770-777. 
Xu R, Shen Q, Ding X, GaO W And Li P. 2011. Chemical characterization and antioxidant activity of an exopolysaccharide fraction isolated from Bifidobacterium animalis RH. Eur Food Res Technol 232: 231-240

ZHAO J, GUI LN, SUN JM, CAO Y AND ZHANG H. 2010. Antioxidative activity of polysaccharide fractions isolated from Tricholoma Matsutake sing. with ultrafiltration. J Life Sci 4: 17-20.

Zheng J, MAo X, Geng L, YANG G AND Xu C. 2014. Production optimization, preliminary characterization and bioactivity of exopolysaccharides from Incutis tamaricis (Pat.) Fiasson \& Niemela. J Taiwan Inst Chem E 45: 725-733.
ZHU LW, ZHONG JJ AND TANG YJ. 2008. Significance of fungal elicitors on the production of ganoderic acid and Ganoderma polysaccharides by the submerged culture of medicinal mushroom Ganoderma lucidum. Process Biochem 43: 1359-1370.

Zonuz AT, RAHMATI A, MortazaVi H, Khashabi E AND FARAHANI RM. 2008. Effect of cigarette smoke exposure on the growth of Streptococcus mutans and Streptococcus sanguis: an in vitro study. Nicotine Tob Res 10(1): 63-67. 
